\title{
CEREBRAL PALSY
}

\author{
BY \\ W. R. F. COLLIS and MARY O'DONNELL \\ From the National Children's Hospital and the Cerebral Palsy Clinic, the Incorporated \\ Orthopaedic Hospital; Dublin
}

This article is written from the point of view of a paediatrician with a wide service, at work in a main centre of population, where reasonable paediatric units for the treatment of ordinary diseases of infancy and childhood are supplied but where provision for the treatment of cerebral palsy has not yet been made. The paediatrician had had no special training in physical medicine, and his knowledge of cerebral palsy was merely that of an ordinary physician, accustomed to occasional cases of 'Little's disease' or 'athetosis' which were brought to his clinic and subsequently referred to the physiotherapy department without a very clear idea of what the physiotherapist should do. Therefore he could give no definite instructions.

One day the subject was suddenly brought to his notice with tremendous force by a case which showed him the terrific drama of a human soul imprisoned within an almost functionless, or at least an abnormally functioning body, yet breaking forth and overcoming apparently unsurmountable disabilities. One of the authors (W.R.F.C.) of this paper had little excuse for his earlier attitude of laissez faire, because he had been aware of the pioneer work done at Queen Mary's Hospital, Carshalton, by his sister-in-law, Mrs. Eirene Collis, whose work for cerebral palsy has been recognized internationally. But a vast amount of clinical work, and the reorganization of paediatrics in every post-war centre, had caused me, from year to year, to postpone a study of the full facts, and thereafter to start a campaign to rescue the children from the back rooms and mental homes where many of them rot away their lives. As we have said, it is usually the single case that rouses our concern. In this instance it was a boy called Christy. He was the child of a mother who had had 21 pregnancies, and had given birth to 16 live children. His was a persistent occipito-posterior birth, accomplished with forceps after much trauma. Resuscitation was difficult, and considerable anoxaemia resulted. Within a few months his mother noticed that he was ' different '; she was familiar with normal children's reactions. Christy could not sit up; when he was lifted up, his head fell back with alarming lack of support, and later his hands began to twist and writhe. As he grew older, he failed to learn to speak, and others seeing him lying flat or writhing on the floor considered him to be mentally deficient. His mother, however, knew that he had intelligence if only it could be reached. (I have subsequently learned that mothers usually do know whether their children are in fact mentally deficient, as in the case of mongols, or whether they are merely prevented from showing their intelligence as happens in the many cases of cerebral palsy).

When Christy was 5 years old, she drew the letter ' $A$ ' on the floor with a piece of chalk. Thus, slowly and painfully she taught him the letters of the alphabet. He always rubbed out the letter with his left heel. The next step was to take the chalk between the toes of his left foot, and to draw the letters himself. In this way he learned to write and read, and a communication with the world was opened. At the age of 9 he discovered that he could draw with his left foot; at 12 he won a painting competition in a Sunday paper. We include a photograph of him painting at this age, and, a picture which he has recently completed in colour (Figs. 1 and 2). An artist commented on this picture that 'it does not appear to show any conscious effort, and apart from the light pencil outlines (which are visible here and there) the colours here seem extraordinarily well washed in, with freedom, and with real sensitivity'.

I met Christy first at a matinee show, arranged by a charity in which I was interested. He was perched on the back of a bigger brother coming out of the theatre. I was struck by the strangely beautiful expression of his face, and by his hunched appearance and athetoid movements. When some years later I heard that something could be done for this group of motor defective children I sought him out in his home. There I learned the story from his remarkable family: the mother who had taught him, the father who had supported him while he passed every motion, holding his uncontrollable athetoid movements in check, and his brothers and sisters who had sustained him down the years in a thousand ways. I was shown his pictures, his drawings, his 
FIG. 1.-Christy painting with his left foot.

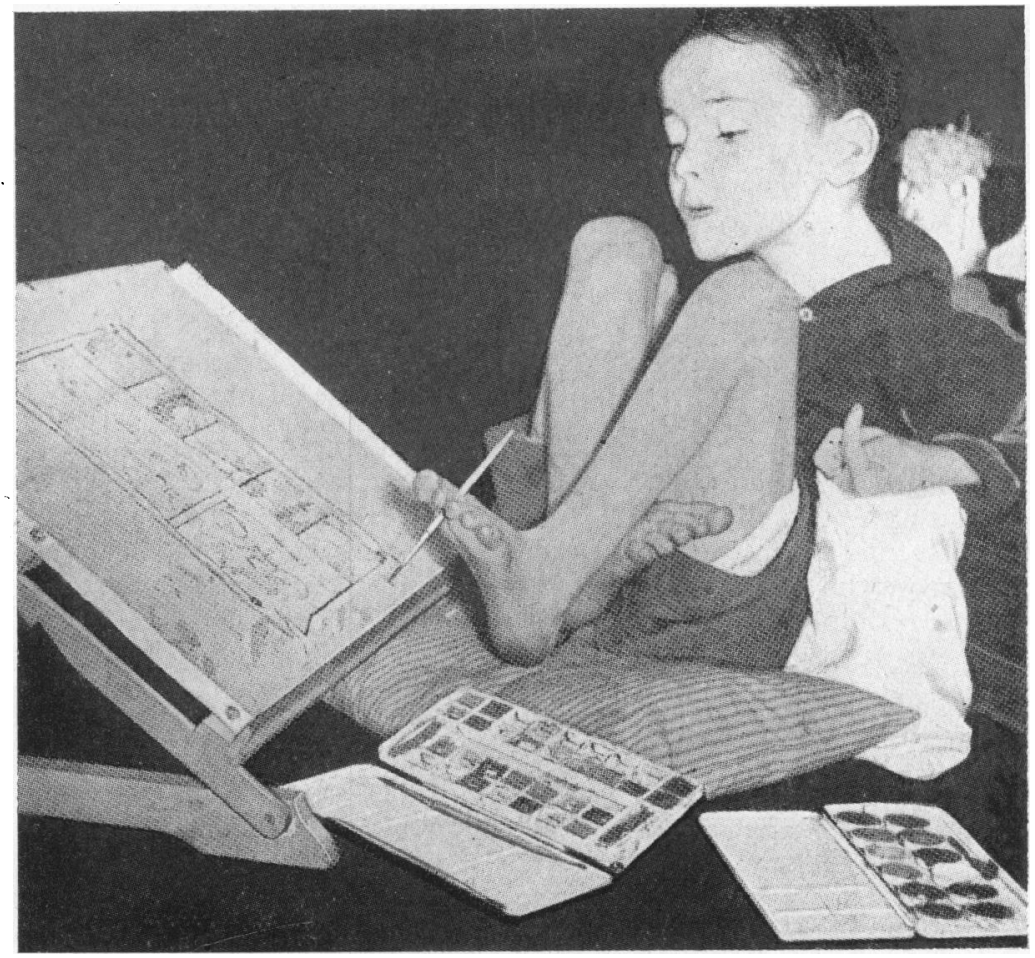

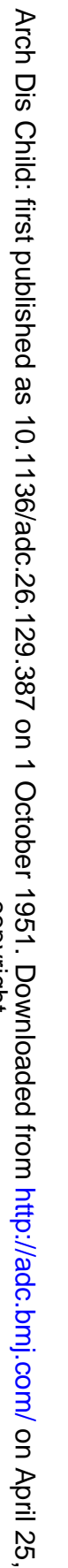

FIG. 2.-A picture by Christy painted with his left foot.

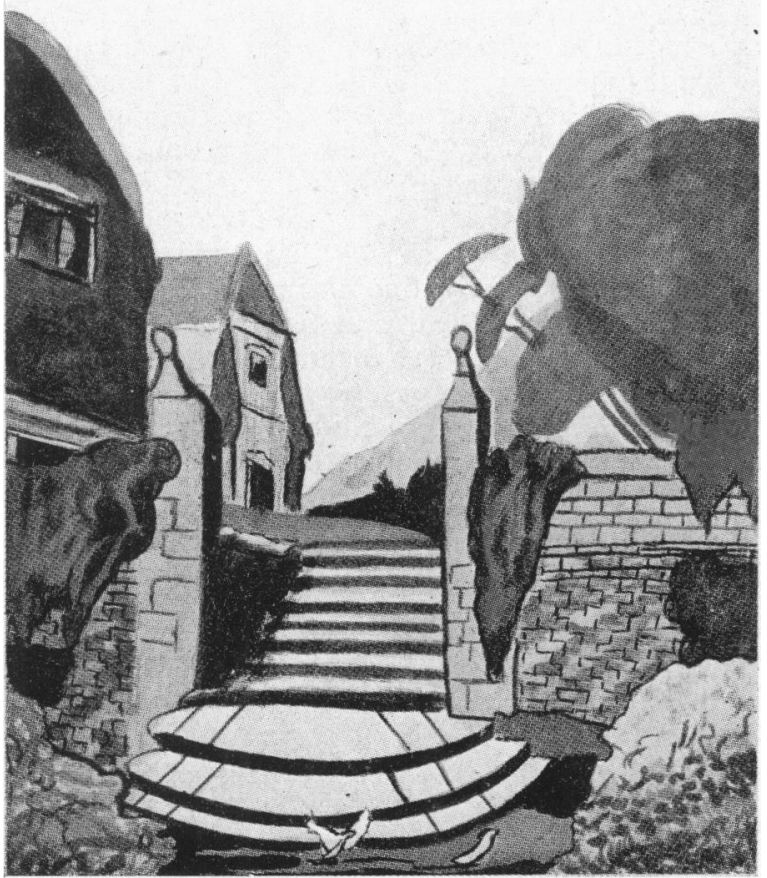

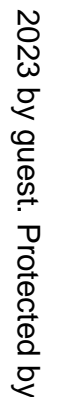


FIG. 3.-A child with tension athetosis.

FIG. 4. - A child with ataxia: note wide base stance.

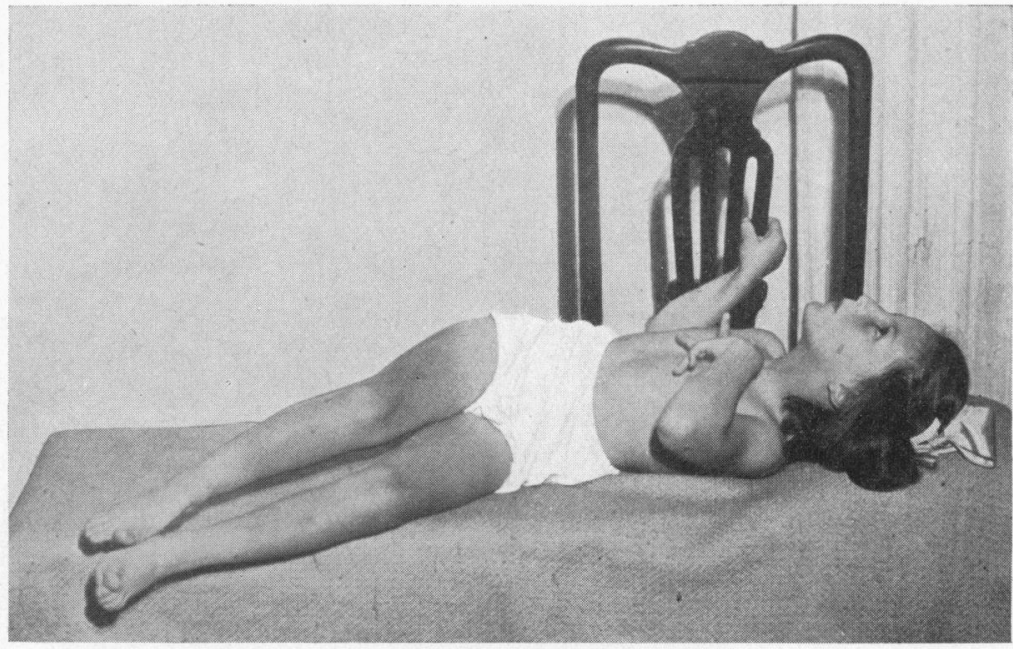

FIG. 3

short stories. The latter were wishful phantasies of the cowboy west and of wild physical action. He sat in the corner in an unusual crouching posture, his famous left foot held ready to write, draw, or clasp a slice of bread and jam. He could not speak, for the incoordination of his larynx was too marked, but he conveyed by unusual sounds and scribbled sentences what he wished to say. The experience of that household, more particularly something that seemed to emanate from the boy, had a stimulating effect on the mind, lifting the normal round of life into the high realms of poetry and beauty.

From that moment it was clear that I must do something, not only for this boy, but for all children who had cerebral palsy in Eire.

Knowledge of cerebral palsy has grown piecemeal during the past hundred years, and a satisfactory definition, embracing all the conditions included in the modern conception of the term, is difficult to formulate. A simple yet reasonably accurate and comprehensive description of the disease is that it consists of a 'difficulty in movement due to the abnormality of any part of the brain that governs movement'.

\section{Types}

Under such a definition cerebral palsy falls into five main types: athetosis, spasticity, ataxia, tremor, and rigidity.

Athetosis. This type of the disease is due to a lesion in the basal ganglia, shown clinically by writhing, snake-like, involuntary movements or violent tremors (Fig. 3). Many athetoids develop a stiffness very like that seen in spasticity, and such patients were usually described as suffering from 


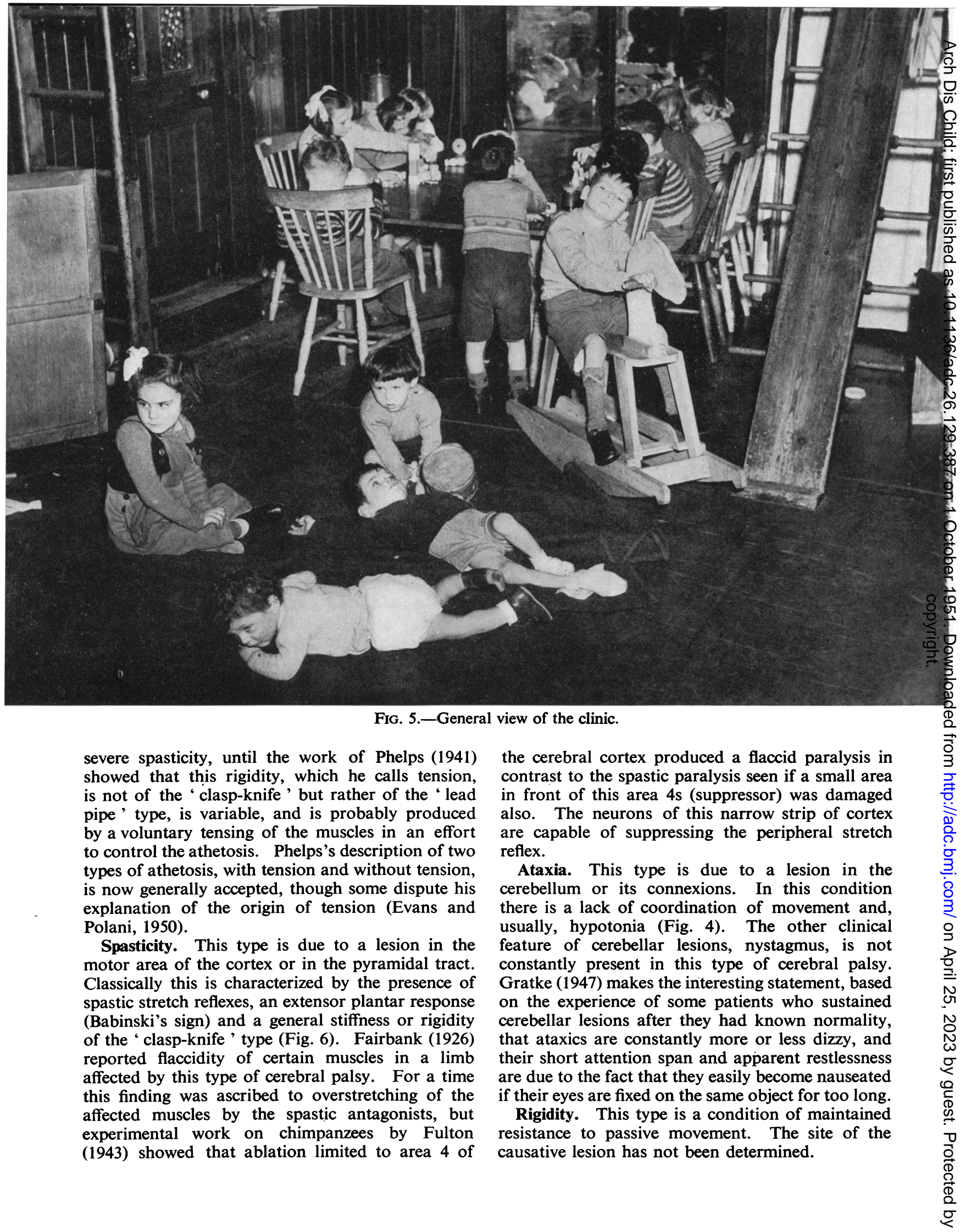


FIG. 6.-Two spastic diplegics on rocking horse, being helped by an older hemiplegic.

FIG. 7.-Bernie being taught to

FIG. 7.-Bernie being taught to
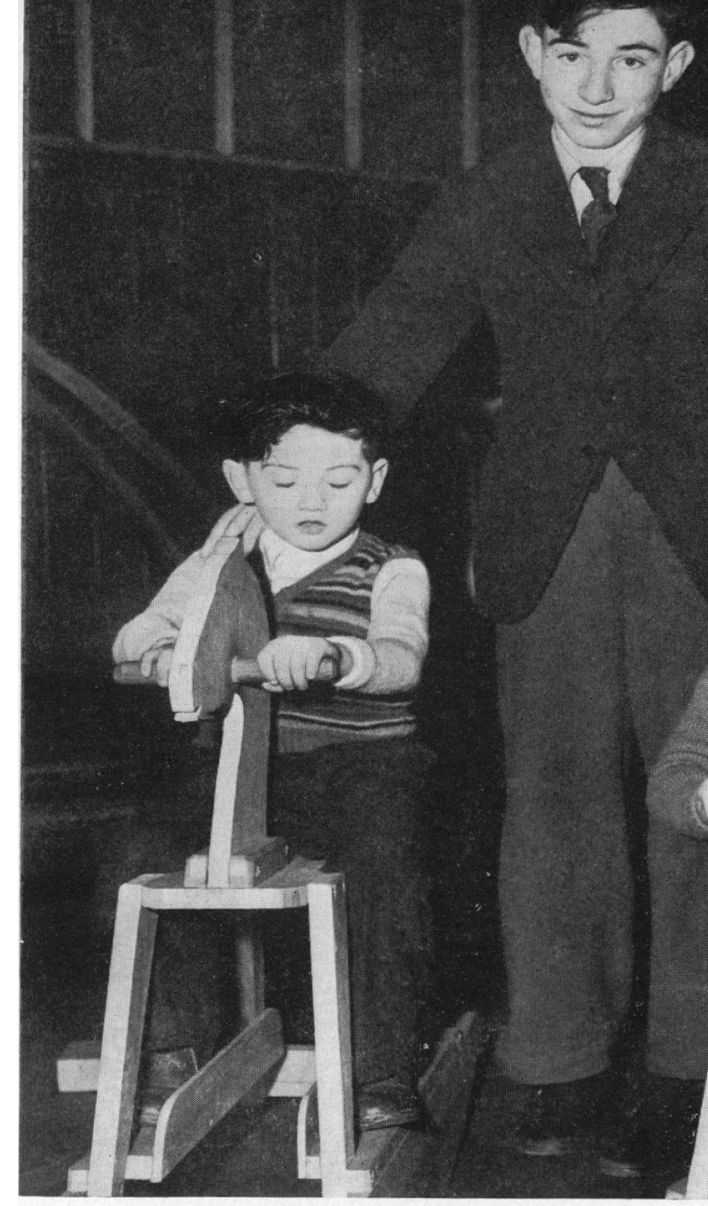

.

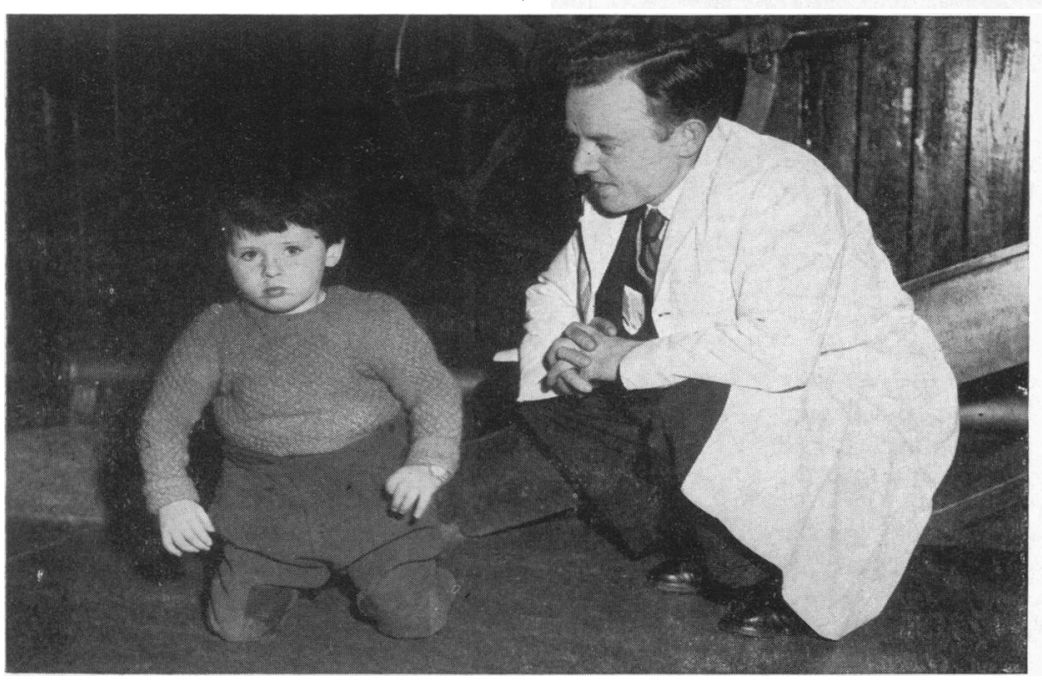

FIG. 7

FIG. 6

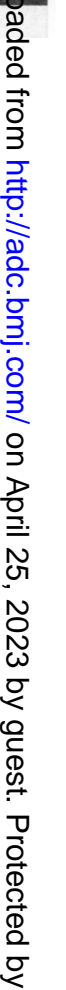


Tremor. This is a condition in which the main clinical feature is a fine rhythmical tremor usually affecting most of the body. Some of the cases are probably due to cerebellar lesions and respond to the methods of treatment applied to ataxics whereas others are typical cases of athetosis and respond to the treatment for that condition.

\section{History}

The outstanding early contribution to the subject is that of W. J. Little (1853) founder of the National Orthopaedic Hospital, London, who introduced tenotomy of the tendo Achillis into Britain. In 1862 he presented a paper to the Obstetrical Society of London on The Influence of Abnormal Parturition, Difficult Labour, Premature Birth and Asphyxia Neonatorum on the Child, especially in Relation to Deformities giving a description of 200 cases observed over the course of 20 years.

Little's observation that many of these patients are in fact intelligent despite their appearance, and that ' treatment based upon physiology and rational therapeutics effects an amelioration surprising to those who have not watched such cases' was unfortunately forgotten for many years. Now his observation has become one of the keystones of our modern approach to the problem of cerebral palsy.

Collier (1924) made a comprehensive survey of the literature and included. Sir Walter Scott's Nick Strumper in The Pirate, a figure in Raphael's Transfiguration, and Shakespeare's surprisingly accurate clinical description of Richard III:

Deformed, unfinished, sent before my time

Into this breathing world, scarce half made up,

And that so lamely and unfashionably

That dogs bark at me as I halt by them.

Collier suggested intra-uterine neuronal degeneration as the underlying cause.

Phelps (1941) clarified the differential diagnosis between the types, and emphasized the different methods of treatment required in each. It is interesting that, like Little, he is an orthopaedic surgeon, yet has played a major part in showing that surgery is of limited value in cerebral palsy, and must in any case form only part of a prolonged scheme of treatment.

Eirene Collis, working at Carshalton since 1943, after studying with Phelps in Baltimore, developed new techniques, especially for the treatment of babies and introduced them into England (Collis, 1947).

The work of McGraw (1943) and of Gesell (Gesell and Amatruda, 1947) on neuromuscular maturation and development in infancy, though not directly concerned with cerebral palsy, contributed to an understanding of the disability caused by the condition, and formed the basis of much of our modern approach.

\section{Aetiology}

Most of the published works on cerebral palsy include a section dealing with aetiology, but despite intensive investigation the primary cause and the relative importance of the various factors concerned have not been determined. There is now general agreement with Ford (1947) who lists three main causes of cerebral palsy.

These causes are first, intra-uterine degenerative and toxic factors which most commonly produce atrophic lobar sclerosis, but may be evidenced by gross cerebral developmental abnormalities or, fairly commonly, microscopical changes with no abnormality visible to the naked eye. The second and third causes listed by Ford are asphyxia neonatorum and cerebral haemorrhage.

It will be noted that prematurity is not included among these causes, though it is a common feature in the history of these cases. Ford accepted the viewpoint of Freud (1897) who wrote that 'premature, precipitate and difficult births are not causal factors in the production of diplegia; they are only associated symptoms of deeper influences which have dominated the development of the foetus or the organism of the mother. The only cerebral paralysis which results from difficult birth occurs when the brain is lacerated and this takes the form of a monoplegia or hemiplegia or rarely of a double hemiplegia, and the anatomical results of this lesion are entirely different from the findings in the brains of diplegia.'

In support of the inclusion of cases with a history of prematurity in the intra-uterine neuronal degeneration group can be quoted Crosse's (1949) finding that $5 \cdot 7 \%$ of premature against $8 \%$ of full term infants (live and stillborn) had congenital abnormalities. An alternative explanation is the greater liability of premature infants to intracranial damage, but there is much evidence against this hypothesis, as will be discussed later.

Collier (1924) supported strongly a prenatal aetiology and explained the theory in simple terms.

\footnotetext{
'If we liken the brain from the commencement of its development to a garden in early spring, well sown with seeds-the neuroblasts, some of which germinate early, some meantime, and some late, those germinating early perhaps of a hardier sort, those germinating late perhaps of a more tender kind, imagine what might be the effect of a noxious influence-a sudden sharp frost for instance, upon this garden. According to its severity and the time when it arrived it might, if it caught all the seeds in a condition of germinating and growth, leave this
} 
garden lifeless. Or it might spare those seeds as yet ungerminated, and those seedlings which had attained sufficient growth and robustness to resist its influence and affect only certain kinds of the seedlings, perhaps according to the state of their development, to their death and destruction. Or the seedlings affected by the frost may not all be killed, some or all of them may be simply "cut" and their leaves for the time withered, and these may be able in some degree to renew their growth and attain a maturity in some cases perfect, in others stunted and imperfect, in all retarded. Lastly, this untoward weather may continue, and crop after crop may perish in a progressive destruction. Some such process as I have put before you in this homely simile of the seedlings and the frost will, I submit, best serve to explain both the aetiology, the symptomatology, and the pathological findings in cerebral diplegia.'

Patten and Alpers (1933) found petechial haemorrhages in 26 of 30 infantile brains removed as a routine or because disease was suspected. In most cases these were capillary haemorrhages under the ependyma of the ventricles, the germinal centres from which neuroblasts and spongioblasts normally migrate to the cortex. They suggest that these haemorrhages destroy the spongioblasts from which the oligodendroglia is derived and interfere with myelinization, and that they are prenatal and not traumatic in origin.

Little, in his earlier paper (1843-4), also emphasized prenatal factors, but in 1862 he wrote: 'A larger proportion of these infants result from asphyxia by the interruption of the proper placental relation of the foetus to its mother and the non-substitution of pulmonary respiration from direct mechanical injury to the brain and spinal cord.' Since then asphyxia neonatorum has retained its evil reputation as a cause of cerebral palsy, but its importance is difficult to estimate since many asphyxiated babies develop normally. Enquiries into the birth histories of selected patients show a high incidence of foetal asphyxia. Faber (1950), for instance, investigated 99 children with mental deficiency, spasticity, or convulsions, and discovered that there had been prolonged apnoea or cyanosis at birth in 22 . Rosenfeld and Bradley (1948) found that the children with a history of asphyxia, that is 28 with a history of difficult resuscitation at birth and 126 who had had severe whooping cough out of 673 admitted to a psychiatric hospital for behaviour disorders, showed a characteristic syndrome of unpredictable variability in mood, hypermobility, impulsiveness, lack of attention, varying inability to recall material previously learned, and conspicuous difficulty with arithmetic. The more satisfactory method of studying the progress from birth onwards of known cases of asphyxia neonatorum has produced conflicting results.
Darke (1944) and Stevenson and Stuart (1950) considered that such children showed later ill-effects, but Keith and Norval (1950) and Campbell, Cheeseman, and Kilpatrick (1950) found no evidence of this. Stewart (1942) suggested that anoxaemia, possibly associated with nutritional deficiency, is a cause of many cases of cerebral palsy, though he also supported Collier's theory.

Perlstein (1949) considered that the infant brain withstands anoxia better than the adult brain, possibly because of a difference in metabolism, carbohydrates being oxidized to lactic acid and not to carbon dioxide and water. In the adult and in some newborn animals anoxia affects the higher cortical centres first, then the mid-brain, basal ganglia, and finally the medullary centres. In the newborn infant the mid-brain and basal ganglia or their cortical connexions, or all three, are most vulnerable and the pyramidal tract is the last to suffer. He suggested that if there is a high carbon dioxide tension in the blood, lack of oxygen is more likely to damage the basal nuclei and the mid-brain, whereas if there is a low carbon dioxide tension anoxia is more likely to affect the cortex. If the anoxia is not due to respiratory obstruction there is hyperventilation, and the carbon dioxide tensory in the blood is low, but if there is respiration obstruction, as in asphyxia livida, carbon dioxide accumulates and the basal nuclei are damaged. This is supported by Evans (1948) who found that $80 \%$ of the athetoids amongst his cases had suffered from asphyxia neonatorum as against $20 \%$ of the spastics and $10 \%$ of a control series. Asher and Schonell (1950) recorded similar figures. At Carshalton, asphyxia livida was a common feature of the early history of all types of cerebral palsy, and asphyxia pallida was usually associated with a widespread lesion and often mental defect, suggesting cortical damage as postulated by Perlestein's theory.

Dr. Sarah McNutt (1885) was the protagonist of birth injury as a major cause of spasticity, and based her view on the necropsy findings in two cases. Collier (1924) and Stewart (1942), amongst others, have opposed her, and Collier showed that her argument was based on doubtful premises. Roberts (1939) followed up 66 cases of intracranial haemorrhage due to birth injury, and found that 40 developed normally, nine had spastic paralysis plus mental defect, and four had an uncomplicated motor defect (two with monoplegia, one with paraplegia, and one with generalized spasticity). Frew (1936) described two babies who lived for a fortnight with extensive cortical haemorrhage, but no cerebral palsy, and the necropsy records of 17 cases of intranatal cerebral palsy with no evidence of cortical haemorrhage, recent or old. Birth injury 
is, however, an important cause of hemiplegia, though half of these cases have a normal birth history (McGovern and Yannet, 1947).

$\mathrm{Rh}$ incompatibility is a recently discovered factor in the aetiology of cerebral palsy. McGovern and Yannet (1947) found that one-third of their quadriplegic cases were due to this condition. Asher and Schonell (1950) reported it in 12 of 75 unselected cases not known to have suffered from kernikterus in their series of 400 , and considered that this was not significantly different from the incidence of $8.2 \%$ in the general population. Evans (1948), too, did not consider it an important cause of cerebral palsy. The few cases of $\mathrm{Rh}$ incompatibility in the Carshalton series had widespread cerebral damage and were mentally defective (Agassiz, O'Donnell, and Collis, 1949), and our experience in Dublin supports this view.

Asher and Schonell (1950) stress the high incidence of neonatal jaundice not due to $R h$ incompatibility in their series, and agree with the conclusion of Baar (1945) that kernikterus is a hepatic encephalopathy and that the bile staining is secondary to the nuclear necrosis.

All the causes of cerebral palsy mentioned so far, except possibly $\mathrm{Rh}$ incompatibility, are prenatal or natal in origin. Most of the remainder are due to vascular thrombosis in the cerebral substance as a result of scarlet fever, measles, whooping cough, mumps and encephalitis or septicaemia (Scheinker, 1946; Lucas, 1949); the three mechanisms by which neurological damage is produced in whooping cough are encephalitis, anoxia, and haemorrhage due to capillary rupture during the paroxysms of coughing.

One of the children attending the Dublin clinic has a traumatic hemiplegia following an accident in which an iron spike was driven through his skull and led to abscess formation.

\section{Treatment}

One of the fundamentals of our modern approach to the treatment of cerebral palsy is that different methods are applied to the different types of the disease. Phelps, writing in 1941, said that:

' The type of training is differentiated with regard to the type of cerebral palsy. Thus in the spastic, reciprocation and reach and grasp, as fundamentals, must be first learned. Surgery then plays an important part in this particular sub-division. Following surgery, re-educational training by further development of reciprocation and the reach and grasp are used to bring about walking and improvement of self help in the arms.

'In the athetoid, the use of relaxation is of fundamental importance, since athetosis disappears or is very greatly diminished by increasing degrees of true relaxation. Following this, motion from the relaxed position is taught. Peripheral surgery has no place in this particular group.

'In the ataxic, balance training is of primary importance. The ataxic, being unable to utilize the automatic balance mechanism must therefore be trained by the cortical substitution of voluntary balance, which is brought eventually to the habit level.'

Phelps also pointed out that some of the difficulties of the child with cerebral palsy may be due to sensory loss or deafness, and that these should be investigated and methods of overcoming them devised, before assuming that a lack of progress is due to a mental deficiency. Phelps described pitch deafness, found especially in athetosis, which may affect part of the pitch range concerned in speech, so that the child is not deaf in the ordinary sense although his speech is indistinct because he hears indistinctly. A suitable hearing aid is of tremendous value in such cases.

Eirene Collis found that the earlier treatment was begun in well selected cases the better were the results. In the Cerebral Palsy Research and Diagnostic Clinic at Carshalton, which now houses 20 children under 5 years of age, in addition to providing out-patient facilities for older children, she has worked out a routine in which all the activities of each child's day fit into the scheme of treatment. She summarized the scope of this work in her contribution to a symposium (1949) on infantile cerebral palsy:

'In all infantile cerebral palsy cases, the child must do the work. The therapist is merely a guide to show him what he must do. Babies make far more rapid progress than do older children. Physiotherapy, as our specific training of these children is called, is not enough; it must be supported by intelligent day long care and supervision, and reinforced by placing the child in varying sleeping postures each night. Every activity may be difficult and must be made easy for every individual child.'

Mrs. Collis considers that if treatment is begun early enough in the right cases splints are unnecessary and surgery is not needed, even for spastics, since the deformities seen in untreated older children are a preventable, secondary development due to faulty posture and attempted normal use of a damaged motor system. In any case the basis of treatment is to take these children as far as possible through the normal stages of motor development, from head and neck control to a control of the trunk and later of the arms and legs. It is possible to give an outline of this treatment as Eirene Collis has done in her book. However, each child presents an individual problem, and his scheme of treatment must be devised to meet his particular case. This scheme should be thought of as a training in movement rather than as a series of exercises, and the 
emphasis must be on the child's performing the movements himself after an initial demonstration by passive movement.

The child is first taught to breathe properly, later he practises flexion and extension of the head and full movements of all the joints of the affected limbs. This work in the spastic is done in the supine and prone positions and sometimes in the lateral position. The athetoid may be allowed to work in whatever position makes relaxation easiest for him; this is usually his sleeping posture. Then he progresses to sitting over the edge of the treatment table, and later to standing, usually with the aid of special skis and ski-poles. When he is able to stand steadily on both feet, the child practises balancing on one leg with the other flexed, and only then does he try to walk. Hence walking is a late accomplishment, attempted only when the child has acquired balance first when sitting, then when kneeling, and finally when standing. This is in striking contrast with the former methods of surgery or of appliances to correct deformities and subsequently encourage walking in any posture. This approach tended to produce the typical 'scissors gait.' Care, however, to prevent equinus developing during the early period of training is very necessary and here there is much to be said for the methods advocated by Denis Browne.

The movements learned as such from the physiotherapist are put to practical use under the direction of the occupational therapist. For example, flexion of the elbow is used to get food or a sweet into the mouth, and when this can be accomplished correctly, self-feeding may be allowed. Speech therapy for those who need it follows control of the respiratory movements, and of the muscles concerned in articulation, e.g. largely those used in swallowing. School activities must also fit into the therapeutic programme so that close team work between all concerned in the re-education of the cerebral palsied child is assured.

The need for special schools for these children is only too obvious, and many have been started in America and England under the influence of Phelps and especially of Carlson (1937), himself an athetoid, who has qualified as a doctor. Some of these schools, such as St. Margaret's, Croydon, are boarding schools; while others such as Carlson House, Birmingham, and the Australian schools, are day schools. Day schools have the advantage of allowing the pupils to have a normal home life. If the parents are reasonably intelligent and cooperative they can carry out some of the treatment at home, and can at least manage their children in such a way that their progress is not hindered. At Carshalton an interesting solution of this problem has been found. Several children over 5 years of age live in lodgings near the hospital with their mothers, and attend the Cerebral Palsy Clinic for treatment, and a special class in the hospital school for education.

\section{The Problem in Dublin}

Having acquainted myself with the above complicated picture, the next step was to apply this knowledge to local conditions and get started. I was immediately confronted with the problem which all organizers in this field encounter at the beginning: the extreme difficulty of conveying a comprehensive picture of cerebral palsy and its needs to my medical colleagues as well as to the lay authorities. The former tended either to be too busy to listen to the whole story, or were convinced that they knew about it already, and they stated that excellent ' results' were obtained in the ordinary physiotherapy departments of their hospitals. The established physiotherapists, on the other hand, regarded my attitude as a criticism of their competency. Charitable organizations were put off by the extreme complexity of the problem and claimed that it was clearly a matter for the government to consider. The attitude of the government officials was characteristic: as a resident clinic did not exist for cerebral palsy, no such clinic could be recognized.

Eventually I succeeded, after much difficulty, in persuading a charitable organization to give me a grant with which to buy equipment and to train a staff. I sent one of my assistants who specialized in a physical approach to psychological problems, and a young physiotherapist, who has a university arts degree as well, to Carshalton for training in the clinic there, and on their return organized an out-patient clinic in the National Childrens' Hospital, Dublin, to which I am attached as visiting physician. Turmoil ensued, the hospital physiotherapist complained to the chairman of the board that she was being unfairly treated. The matter became so unpleasant that it was necessary to move the clinic elsewhere. Fortunately by now the subject had received a certain amount of general support, and the Orthopaedic Hospital Board was persuaded by Mr. C. Somerville-Large, one of their senior surgeons, to house the clinic in their gymnasium and to give it every facility. Great care was taken to avoid upsetting the established physiotherapy staff; a very satisfactory arrangement was made, and a medical orthopaedic clinic was organized inside a surgical orthopaedic hospital. It was probably the first of its kind. It has worked extraordinarily well; both sides benefit greatly from a mutual exchange of knowledge, and this exchange is not limited to knowledge about cerebral palsy. 
Shortly after the establishment of this clinic in the Orthopaedic Hospital, the second author (M.O'D.) returned to Dublin after three years in Carshalton Clinic, and is now in charge. The clinic (Fig. 5) is held every morning in the hospital gymnasium. The children are brought to and from the clinic from various parts of the city and its surroundings in ambulances (supplied by the St. John Ambulance Brigade, the Red Cross, and the Knights of Malta). In addition several private cars are available for transport.

Sixty cases, selected from over 100 referred for examination, attend; some daily, some three times weekly, some less frequently.

Twenty or more children in one room, all capable of adding to the general din despite their varying degrees of handicap, are not conducive to quietness, but most of them do individual work well in a quiet corner, and there is a keen spirit of competition between those with similar disabilities.

Those of school age who are able to walk, particularly hemiplegics, attend ordinary schools when they are not at the clinic. This arrangement is clearly unsatisfactory for most of them, but at present no alternative school is available.

The therapeutic programme, as well as the transportation facilities, depend largely on voluntary helpers. Of the staff of six, only three are paid, the doctor in charge, the physiotherapist, and one attendant. The local authority has agreed to pay 3s. an attendance; the remaining expenses are met by voluntary funds.

Each child is given specific treatment, based on the principles outlined already, lasting from a few minutes to half an hour according to his attention span. The youngest children especially are often given a few short periods of treatment rather than one long one.

For the rest of the morning (Fig. 5) the children play under supervision, and most of them thoroughly enjoy the rocking horses, slide, and swing which have been provided by wellwishers. Handwork with plasticene, blocks, balls, and a large spinning top are an informal type of occupational therapy in the guise of play. A large counting frame with cotton reels instead of balls is the most recent acquisition.

Half-way through the morning there is a break for milk, heated if necessary, and biscuits. This gives an opportunity of teaching some of the children to chew and swallow, or to feed themselves.

The routine of one child, Bernie, may be given as an example. She is an athetoid born on January 20,1946 , at home, the youngest of seven children; she was collapsed at birth and needed resuscitation with alternate hot and cold water. She did not attempt to sit up until she was 1 year old, or try to walk until she was 3 years of age, and from the age of 2 years her movements were noticed to be jerky. Bernie began treatment about one year ago and has progressed through the stages of relaxation and movement on the table to sitting unsupported and recently kneeling (Fig. 7). After practising kneeling for a short time, she is allowed to crawl where she wishes; usually she crawls first to the slide and crawls up the steps to the platform. During the mid-morning break she sits at the table and eats the biscuits unaided but still needs help with the milk. Later she has a swing and likes to be pushed higher than anyone else. She is very proud of her ability to kneel and practises this many times during the morning, so often in fact that she has to be stopped since her efforts cause a return of marked athetoid movements. Her speech is indistinct and often barely audible though intelligible, and she is made to express her wishes loudly and clearly.

Apart from the equipment mentioned already the clinic has chairs adapted with groin straps and foot rests as recommended by Mrs. Collis, but there are not yet as many of these as are required. In addition to a large ordinary table there is a small table with two semicircular pieces cut away for children who need considerable support for their arms while working with their hands. Later special skis and ski-poles will be required for children such as Bernie when they are learning to stand, balance on one leg, and walk. Only one child has a splint, and he is a hemiplegic who wears a cock-up splint for his affected wrist. None of our cases wear braces or leg splints.

In other words a start has been made, and although a clinic of mixed age groups adds greatly to the problem of those in charge it has proved to have certain advantages as well. Christy, for instance, is now our doyen, and although 17 , is a real help to us all. He keeps a watchful and kindly eye on the activities of the younger children. His smile of approval for work well done is highly prized. This elasticity of the clinic has made it possible for us to take in some children belonging to the educated classes. Fortunately cerebral palsy, unlike certain other crippling conditions like rickets, is not chiefly confined to the poor and the destitute who tend to be inarticulate. Hence the news that something is being done for this group of crippled children has got round, and many people have come forward with offers of help.

Two needs immediately make themselves evident: first, the need for a special school for cases which have come to the clinic too late to be rehabilitated sufficiently so that they can attend ordinary schools, and for those whom rehabilitation can never go far 
enough to make them eligible for ordinary schools. The second need is for a resident clinic for children from 9 months to 5 years, the age at which real and lasting progress can be made. The establishment of a special school involves the educational authorities, and a committee is at present considering the whole problem of the provision of schools for physically defective children. Cerebral palsy, because of the start already made, can now claim its place in the coming scheme.

After the out-patient clinic had been running for less than a year we, the National Committee for Cerebral Palsy, Ireland, were offered a house in a beautiful suburb of Dublin (Killiney) for a resident clinic. This house has now been fitted out by voluntary effort, and officials of the central government have gone so far as to say that when it is functioning they may recognize it as a clinic to which local authorities can send cases for which they are paying. Public opinion seems now to be in a favourable mood, and as a result our Committee is venturing to open this residential clinic during the next month. It appears indeed that we have succeeded in launching in Ireland a scheme for the treatment of cerebral palsy along the most modern lines, and while accepting help from society at large and central or local government authorities, we have yet kept control of the scheme and have not allowed it to be turned into a minor department of physical medicine or a state-run institution.

It is too soon to talk about results, but already such progress has been made with many of the children, and such gratitude shown by the parents, that our voluntary workers, instead of tiring of their strenuous routine, have become more enthusiastic and the whole enterprise has acquired an amazing spirit of gladness.

\section{Discussion and Summary}

An attempt has been made to describe the problem of cerebral palsy and its pitfalls as it presented itself in an area where, up to date, nothing had been done for the problem.

The present authors were fortunate in being in close contact with Eirene Collis. Without her aid it would have been all too easy to have got started on the wrong foot, to have regarded the conditions as a mere problem of physiotherapy, and to feel that the appointment of special physiotherapists was all that was necessary.

In the organization for this work the following principles stand out: early diagnosis, if possible during the first weeks of life; careful differentiation into type; early treatment which will prevent deformities from occurring and later the necessity for splints and surgery; and, in cases where diagnosis is late, combined psychological, medical, and surgical treatment will often be necessary, the emphasis being on the word combined. Surgical treatment by itself will usually make the patient worse, but a lengthening of the tendo Achillis, for instance, in a case of hemiplegia with difficulty in walking due to an equinus deformity, if combined with the right psychological approach and correct exercises will often greatly benefit the child and expedite matters.

Training must aim at complete rehabilitation so that the child will be able to attend the ordinary school, and later earn his own living. Where he arrives at the clinic too late for this, or is too severely affected a case, a special school is necessary, and later special arrangements must be made to find him suitable employment when adult life is reached. Finally it is clear that any doctor who would specialize in this difficult branch of medicine must be prepared to start with the baby and end with the fully grown man. He must be able to take the long view; he must always look beyond the moment, see the whole picture, and be flexible in his approach, treating each child differently. Above all he will need patience.

I wish to thank the editors of the Archives of Disease in Childhood for doing me the honour of asking me to contribute to this special number on the occasion of the 80th birthday of Sir Robert Hutchison, my master, to whom I owe a life long debt of gratitude for all he taught me and all the kindness he showed me when a young man in London. (R. C.)

\section{REFERENCES}

Agassiz, C. D. S., O'Donnell, M. B., and Collis, E. (1949). Lancet, 2, 1030

Asher, P., and Schonell, F. E. (1950). Archives of Disease in Childhood, 25, 360.

Baar, H. S. (1945). Austrian Med. Bull., 1: Special issue.

Campbell, W. A. B., Cheeseman, E. A., Kilpatrick, A. W. (1950). Archives of Disease in Childhood, 25, 351.

Carlson, E. R. (1937). Ann. intern. Med., 11, 324.

Collier, J. (1924). Brain, 47, 1.

Collis, E. (1947). 'A Way of Life for the Handicapped Child.' London.

(194\%). Lancet, 2, 239.

(1949). Physiotherapy, 35, 146. Crosse, V. M. (1949). 'The Premature Baby.'

Darke, R. A. (1944). J. Pediat., 24, 148.

Evans, P. R. (1948). Archives of Disease in Childhood, 23, 213. and Polani, P. E. (1950). Quart. J. Med., 19, 129.

Faber, H. K. (1950). J. Pediat., 37, 326.

Fairbank, H. A. T. (1926). Brit. med. J., 1, 776.

Ford, F. R. (1947). ' Nervous Disorders of Infancy and Childhood.' Springfield, Illinois.

Freud, S. (1897). 'Der infantile Cerebrallähmung.'

Frew, R. S. (1936). ' 'Disease in Childhood.' London.

Fulton, J. F. (1943). "Physiology of the Nervous System,' 2nd ed. London. 
Gesell, A., and Amatruda, C. S. (1947). 'Developmental Diagnosis,' 2nd ed. New York.

Gratke, J. M. (1947). J. Speech Dis., 12, 129.

Keith, H. M., and Norval, M. A. (1950). Proc. Mayo Clin., 25, 11.

Little, W. J. (1843-4). Lancet, 1, 319. (1853). Ibid., 2, 120.

(1862). Trans. obstet. Soc. Lond., 3, 293.

Lucas, H. K. (1949). 'The Cerebral Palsies of Childhood.' Sanderstead.

McGovern, J., and Yannet, H. (1947). Amer. J. Dis. Child., 74, 121.

McGraw, M. B. (1943). ' The Neuromuscular Maturation of the Human Infant.' New York.
McNutt, S. (1885). Arch. Pediat., 2, 20.

Patten, C. A., and Alpers, B. J. (1933). Amer. J. Psychiat., 89, 751.

Perlstein, M. A. (1949). Nerv. Child., 8, 128.

Phelps, W. M. (1941). Sth. med. J., Bgham, Ala, 34, 770.

Roberts, M. H. (1939). J. Amer. med. Ass., 113, 280.

Rosenfeld, G. B., and Bradley, C. (1948). Pediatrics, Springfield, 2, 74

Scheinker, I. M. (1946). Arch. Neurol. Psychiat., Chicago, 55, 216.

Stevenson, S. S., and Stuart, H. C. (1950). Amer. J. Dis. Child., 79, 931.

Stewart, R. M. (1942). Proc. roy. Soc. Med., 36, 25. 